\title{
Technical Product Policy Improvements in Machine-Building Enterprise
}

\author{
Anton N. Karamyshev \\ Kazan Federal University \\ Email: antonkar2005@yandex.ru
}

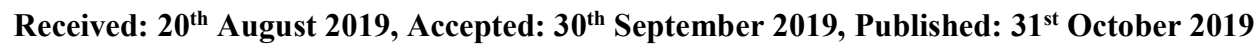

\begin{abstract}
Many models for assessing the maturity of the process management system of an enterprise (in particular, "CMMI"; "classification of the states of the process management system in industrial enterprises" proposed by A. Karamyshev, I.I. Makhmutov, S.A. Sych, a five-level maturity model "BI", etc.) the highest level is called the pursuit of excellence. At this level, there is a continuous improvement of all subsystems of the enterprise and increase its overall competitiveness. However, quantitative methods that implement the pursuit of excellence have not been proposed. Currently, the implementation of the highest level of maturity of process management is, in many ways, a non-systemic process. Authors and researchers that deal with the enterprise management systems based on business processes understand pursuit of excellence as the optimization of almost any activity. In this regard, the task of systematically determining the most significant and giving maximum economic effect points of application of effort is relevant. This article proposes a model of permanent improvement of the product policy of a large machine-building enterprise, which allows determining products with low profitability, to plan measures to increase the specific and total profit, taking into account the share of overhead costs of the enterprise attributable to the cost of each type of manufactured products.
\end{abstract}

Keywords

Profitability, Optimization, Enterprise Management, The Maturity of the Business Process, Improvement of Activities.

\section{Introduction}

The task of forming a production plan that maximizes the total profit from the sale of marketable products is relevant for large industrial enterprises. The basis for making a management decision to include certain products in the production plan are economic indicators (specific profit and profitability of production). Also, a production plan should take into account the following important factors:

$>$ The assignment of part of the overhead costs to the cost of low-profitable production. The exclusion of such products from the production plan will lead to a redistribution of these costs to the rest of the manufactured products, which will lead to an increase in unit cost. Under these conditions, it is advisable to exclude low-profitable products from the production plan only if there is the possibility of quick loading of the released production capacities by the production of products with higher profitability.

$>$ Overhead costs of an enterprise amount to 15 percent or more in the total costs of an industrial enterprise [1,2]. An important is the task of their reasonable distribution on the products. The most common for industrial enterprises methods for allocating overhead costs to the cost of goods ("boiler" and derivatives derived from it, in which the distribution of overhead costs is carried out in one or several stages) distort the cost of production in terms of overhead due to methodological problems of their justified distribution. This distortion is expressed in an increase in the value of one product and a decrease in the value of another, i.e. one product subsidizes another.

\section{Main Part}

The solution to the problem of assigning overhead costs (they form the cost of auxiliary business processes) was proposed in the $\mathrm{ABC}$ method [3-5], the methodology of task-based engineering [6], methods for multi-base distribution of the cost of auxiliary business processes [7] and its upgraded version - the multi-cyclic distribution method [8].

The specific features of a large machine-building enterprise complicate the reasonable calculation of the cost of production. In these conditions, in our opinion, it is most advisable to use the methodology of multi-cycle calculation of production costs (the rationale for this conclusion and a detailed analysis of the above methods and techniques are presented in the author's material [8-13]).

In order to form an optimal production plan at large machine-building enterprises, we developed a model (Fig. 1), based on the method of multi-cycle distribution. 


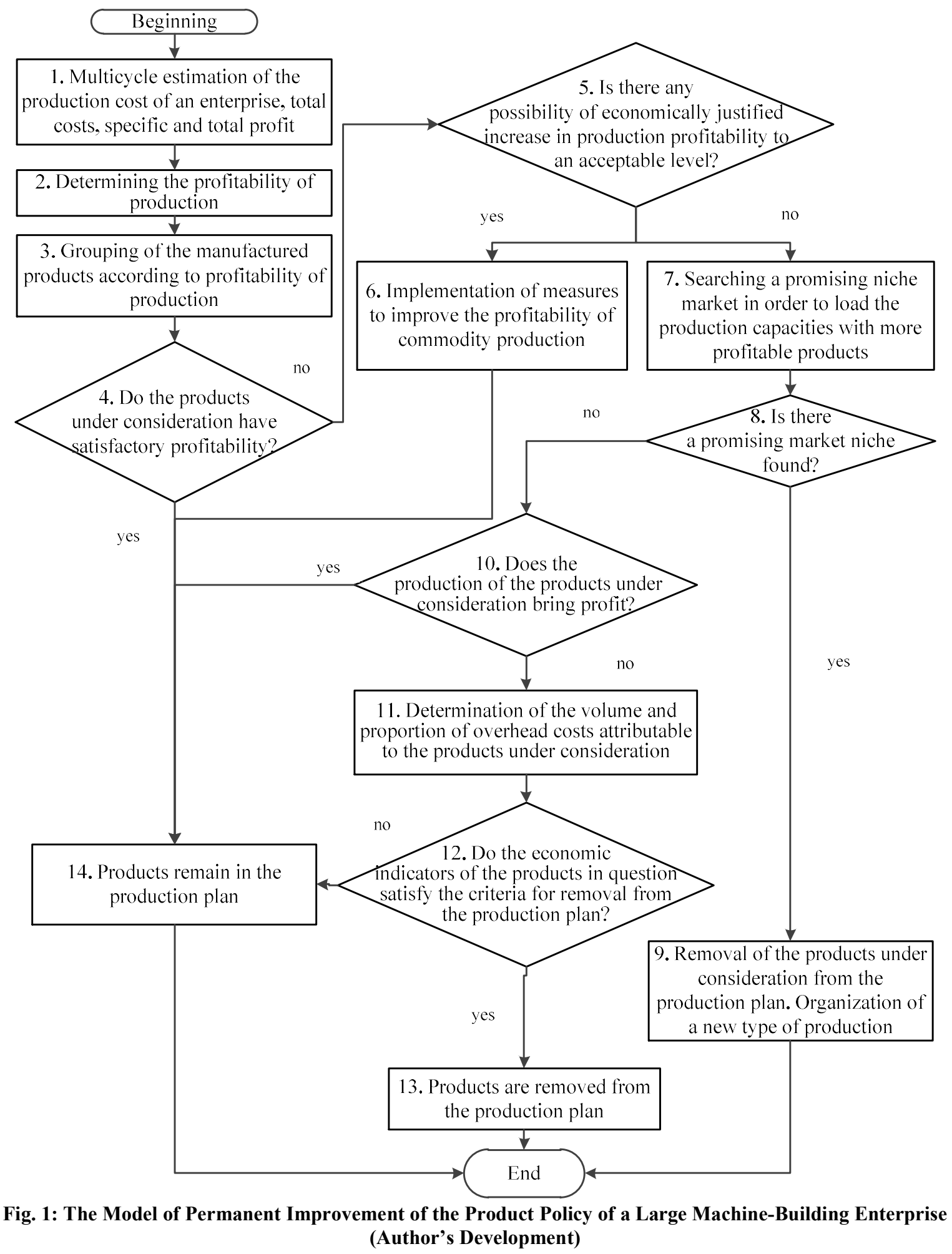

We shall consider the stages of the proposed model.

Stage 1. Multicycle Estimation of the Production Cost of an Enterprise, Total Costs, Specific and Total Profit. The multi-cycle distribution [8] is a calculation-analytical method that involves the calculation of the technological cost of a product based on direct costs, and the overhead cost per product is determined by the distribution of their cumulative value first to the main business processes, and then to the products in proportion to certain bases distribution over several cycles. 
The technique of multi-cyclic distribution makes it possible to analyze the cost in the context of specific variables and fixed costs.

Stage 2. Determining the Profitability of Production.

The profitability of production of $i$-th product $\left(P P_{i}\right)$ is calculated by the formula:

$P P_{i}=\frac{N I_{i}}{E_{i}} \times 100 \%$

$N I_{i}$ - net profit for the i-th type of product;

$E_{i}$ - costs of production and sale of the $i$-th type of product.

It should be noted that the profitability of sales can act as an alternative indicator on both this and the subsequent stages of the methodology.

The profitability of sales of $i$-th product $\left(R O S_{i}\right)$ is calculated by the formula:

$R O S_{i}=\frac{N I_{i}}{N S_{i}} \times 100 \%$

$N S_{i}$ - revenue from the sale of the $i$-th type of product.

Stage 3. Grouping of the Manufactured Products According to the Profitability of Production.

At this stage, the products are assigned to one of 2 groups: products with satisfactory and unsatisfactory profitability for the enterprise.

The purpose of this grouping is to determine the types of products with unsatisfactory profitability of production, which first of all need to be focused on and to develop further measures based on them, aimed at increasing indicators of economic efficiency.

In our opinion, the profitability of production should be considered acceptable if it is higher than or equal to the average level of profitability of production of competing companies in this industry, which, among other things, should ensure the investment attractiveness of the company.

Stage 4. Do the Products Under Consideration have Satisfactory Profitability?

Depending on the answer to the question above, two scenarios are possible:

$>$ if the $i$-th product has satisfactory profitability of production, then it is left in the production plan;

$>$ Otherwise, we proceed to stage 5 of the model.

Stage 5. Is there any Possibility of an Economically Justified Increase in Production Profitability to an Acceptable Level?

As possible ways to increase the profitability of production of $i$-th products, we can point to the improvement of the technological base of the enterprise (modernization projects should be economically viable and justified) and the search for additional sales markets. The implementation of these measures is aimed at reducing unit costs for the production of the $i$-th product, which will lead to an increase in profit and profitability.

If the implementation of these measures will increase the profitability of production to an acceptable level, then the i-th product is left in the production plan. Otherwise, we proceed to search for other, more promising and profitable market segments.

Stage 6. Implementation of Measures to Improve the Profitability of Commodity Production.

The above measures are being implemented.

Stage 7. Searching a Promising Niche Market in Order to Load the Production Capacities with more Profitable Products.

Search for and assessment of the possibility of developing a promising market niche should be carried out subject to the personnel and technological capabilities of the enterprise. This stage involves the implementation of marketing activities in order to search for a promising market segment and assess the ability of the enterprise to produce the necessary products at a certain price.

Stage 8. Is there a Promising Market Niche Found?

If a promising market niche is found and the production of new products is possible, we proceed to the stage of organizing its production. Otherwise, we proceed to the stage of evaluating the values of overhead costs attributable to the $i$-th product.

Stage 9. Removal of the Products Under Consideration from the Production Plan. Organization of a New Type of Production.

Organization of production includes the stages of product design, development of production technology, purchase, and commissioning of additional equipment.

Stage 10. Does the Production of the Products Under Consideration bring Profit?

If the product has low profitability of production, produces small profits and gives no chance to replace it with a more profitable one, then it must be left in the production plan.

Stage 11. Determination of the Volume and Proportion of Overhead Costs Attributable to the Products under Consideration.

The multi-cycle distribution method [8] makes it possible to allocate overhead costs in the cost of production.

Stage 12. Do the Economic Indicators of the Products in Question Satisfy the Criteria for Removal from the Production Plan? 
Unprofitable products, which account for a small proportion of overhead and general business expenses, are offered to be excluded from the production plan. Moreover, its exclusion from the production plan should not affect competitiveness at the price of other types of marketable products.

We offer the following criteria for the exclusion of the $i$-th product from the production plan:

$\left|L_{i}\right| \rightarrow F C_{i}$

where $L_{i}$ - the loss from the sale of the $i$-th product for a certain period of time (the value must be taken modulo);

$F C_{i}$ - the sum of overhead expenses allocated to the cost of the $i$-th product for the same period of time.

The loss from the production of unprofitable products is compared with the amount of overhead allocated to these products. If the loss is less than the sum of the overhead costs allocated to it, then these products must be left in the production plan of the enterprise. Otherwise, this sum of overhead costs will be redistributed to the rest of the enterprise's marketable products, which will increase its cost and reduce competitiveness in price.

Stage 13. Products are Removed from the Production Plan.

Unprofitable products that meet the above criteria are excluded from the production plan.

Stage 14. Products Remain in the Production Plan.

The following products remain in the production plan:

$>\quad$ Products with satisfactory profitability;

$>\quad$ Profitable products with low profitability, which can be increased by the implementation of certain organizational and technical measures;

$>\quad$ Profitable products with low profitability, which is impossible at the time of the decision to increase the implementation of certain organizational and technical measures and replace more profitable;

$>$ Unprofitable products that do not meet the proposed criteria for exclusion from the production plan.

\section{Methods}

The study applied the following methods:

1. A selective analysis of specialized literature with a high citation index for the topics indicated in the title of the article. In particular, information was collected on the methods for the distribution of overhead costs, taking into account the specific features of large machine-building enterprises.

2. The generated array of information was systematized for the purpose of further analysis. In particular, based on an analysis of the available methods and methodologies a model was proposed for the permanent improvement of the product policy of a large industrial enterprise, and its advantages and disadvantages were identified.

3. The authors interpreted the results of the study and made conclusions.

\section{Results and Discussion}

The exclusion of low and unprofitable products from the production plan leads to a redistribution of part of the overhead costs to the cost of other products, worsening its competitiveness in price.

Given the methodological difficulties of accurately calculating the cost of production, the determination of low and unprofitable products is a problematic task for large engineering enterprises. For this reason, the formation by existing methods of a product policy that maximizes the financial results of the enterprise is also problematic.

\section{Summary}

The proposed model of permanent improvement of the product policy of a large industrial enterprise allows us to systematically determine the points of application of effort in order to improve the performance of the enterprise, to develop and implement the necessary organizational and technical measures.

\section{Conclusions}

The proposed model is based on the author's method of calculating the cost of production of a large machine-building enterprise, taking into account the principle of multi-cyclical distribution of the cost of auxiliary business processes.

\section{Acknowledgments}

The work is performed according to the Russian Government Program of Competitive Growth of Kazan Federal University.

\section{References}

[1] Mickiewicz, A. 2007 Distribution of complex costs in accounting. Examples // Economics and life. 2007. No. 3. C.4-5 (adj.)..

[2] Sych, S.A., Shamov, V.A., Saraykin, A.V. 2008 Method of multi-basis distribution of overhead costs: a new look at the ABC-method // Management accounting. №6. P.36-45.

[3] Kaplan, R.S., Anderson, S.R. 2007 Time-driven activity-based costing. A simpler and more powerful path to higher profits. Harvard Business Scholl Press. 220 p.

[4] Shamaev, I. Activity-based costing and activity-based budgeting. Retrieved from: https://ivan-shamaev.ru/activity-based-costing-and-activity-based-budgeting 
[5] Telnov, Yu.F. (2005). Reengineering of business processes. Component methodology. Moscow: Finance and Statistics. 320 p.

[6] Smirnov, Yu.N. 2008 Methodology of budgeting of business processes of the enterprise // Integral. No. 4. P.7475.

[7] Makhmutov, I.I., Karamyshev, A.N., Sych, S.A.. 2008 Methodology for assessing the services of auxiliary units // Integral. - No.6. P.68-70.

[8] Karamyshev, A.N. (2016). A technique for calculating the cost of production of a large machine-building enterprise, taking into account the principle of multicyclic distribution of the cost of auxiliary business processes // Economics and Entrepreneurship. № 12 (Part 3). P.1054-1061.

[9] Karamyshev, A.N. 2017 Multicycle principle of attributing the cost of supporting business processes to commodity production cost in large industrial enterprises // Turkish Online Journal Of Design Art And Communication. Vol.7, Is. - P.1675-1685.

[10] Karamyshev, A. N 2018 Analysis of Existing Approaches to Management of Industrial Enterprises // HELIX. Vol.8, Is.1. P.2893-2897.

[11] Karamyshev, A.N. 2017 The analysis of algorithms of adoption of basic administrative decisions at Industrial Enterprises//REVISTA PUBLICANDO. Vol.4, Is.13. P.472-487.

[12] Karamyshev A.N. 2017 Analysis of managerial decisions on the modernization of technologies for the implementation of basic and auxiliary business processes of an industrial enterprise // Economics and Entrepreneurship. №2 (Part. 2 P.816-820.

[13] Karamyshev A.N. 2017 Analysis of managerial decisions on expanding the range and increasing production volumes // Economics and Entrepreneurship. P.833-836. 